Review

\title{
Pygidial Glands in Carabidae, an Overview of Morphology and Chemical Secretion
}

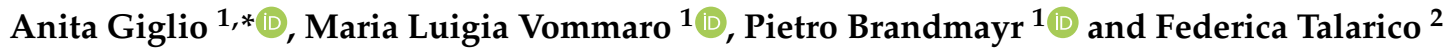 \\ 1 Department of Biology, Ecology and Earth Science, University of Calabria, 87036 Rende, Italy; \\ marialuigia.vommaro@unical.it (M.L.V.); pietro.brandmayr@unical.it (P.B.) \\ 2 Natural History Museum and Botanical Garden, University of Calabria, 87036 Rende, Italy; \\ federica.talarico@unical.it \\ * Correspondence: anita.giglio@unical.it; Tel.: +39-0984492982; Fax: +39-0984492986
}

Citation: Giglio, A.; Vommaro, M.L.; Brandmayr, P.; Talarico, F. Pygidial Glands in Carabidae, an Overview of Morphology and Chemical Secretion. Life 2021, 11, 562. https://doi.org/ $10.3390 /$ life11060562

Academic Editor: Dmitry L. Musolin

Received: 18 May 2021

Accepted: 12 June 2021

Published: 15 June 2021

Publisher's Note: MDPI stays neutral with regard to jurisdictional claims in published maps and institutional affiliations.

Copyright: (c) 2021 by the authors. Licensee MDPI, Basel, Switzerland. This article is an open access article distributed under the terms and conditions of the Creative Commons Attribution (CC BY) license (https:// creativecommons.org/licenses/by/ $4.0 /)$.

\begin{abstract}
Predator community structure is an important selective element shaping the evolution of prey defence traits and strategies. Carabid beetles are one of the most diverse families of Coleoptera, and their success in terrestrial ecosystems is related to considerable morphological, physiological, and behavioural adaptations that provide protection against predators. Their most common form of defence is the chemical secretion from paired abdominal pygidial glands that produce a heterogeneous set of carboxylic acids, quinones, hydrocarbons, phenols, aldehydes, and esters. This review attempts to update and summarise what is known about the pygidial glands, with particular reference to the morphology of the glands and the biological function of the secretions.
\end{abstract}

Keywords: allomone; chemical ecology; defensive secretion; gas chromatography; ground beetles; microscopy; morphology

\section{Introduction}

The carabid beetles (Coleoptera, Carabidae) include approximately 40,000 described species that are ecologically important as predators in many ecosystems and range in feeding habits from generalist to specialists [1,2]. Carabids are often used as indicators because they are extremely sensitive to environmental changes [3-5]. Their ecological role in the trophic web of agroecosystems [6], makes them particularly suitable for monitoring the impact of agrochemicals [5,7,8] and heavy metals [9-13]. Furthermore, as generalist predators, ground beetles provide important ecosystem services by lowering populations of invertebrate pests and weed seeds $[14,15]$. However, carabids are consumed by a number of different species, including invertebrates and insectivorous vertebrates such as birds, mammals, amphibians, and reptiles [1]. Predator-prey interactions are likely the major driving force for the evolution of defences against predators in carabid beetles. Strategies to escape predatory attacks primarily include morphological adaptations, such as cryptic or warning coloration [16-19] and dorso-ventral flattening, large eyes, and long legs to escape [20], as well as secretion of chemical repellents [21-23]. Ground beetles possess a pair of abdominal glands called pygidial glands that produce defensive secretions. The main function of the pygidial glands is to defend against predators, but they also engage in biological activities such as facilitating the penetration of the defensive substances into the integument of the predator and inhibiting the growth of fungi and pathogens [24,25]. A few studies to date have examined the chemical compounds of pygidial gland secretions [26-30] and comparatively investigated their taxonomic significance [22,31-34]. We attempt to review the current state of knowledge on the pygidial glands of carabid beetles by providing an overview of their structure and the chemical compounds of the secretion. 


\section{General Morphology}

Forsyth [35] first proposed a comparative description of pygidial glands in 71 species from 34 tribes to define phylogenetic relationships within Carabidae. Currently, approximately 150 species from 43 tribes have been described (Table 1). The most commonly used examining technique to study pygidial gland morphology is light microscopy (LM). In addition, other techniques such as fluorescence (FM) microscopy, scanning electron microscopy (SEM) and focused ion beam/scanning (FIB/SEM) electron microscopy, (TEM) transition electron microscopy, synchrotron radiation X-ray phase-contrast micro-tomography (SR-PhC micro-CT) are also applied.

Each pygidial gland consists of a variable number of secretory lobes (acini), collecting duct, reservoir chamber, reaction chamber, and efferent duct (Figure 1). These glands (class 3 according to the classification of Noirot and Qhennedey [36,37]) are variable in structure and have been described in several species [35,38]. The lobe or acinus, which is spherical or elongated and enveloped in a thin basal lamina, is a cluster of secretory units, connected to the collecting duct by a conducting duct that drains secretions outward. The secretory unit consists of two parts, an elongated, cube-shaped secretory cell surrounding a receiving duct and a duct cell surrounding the conducting duct [35,39-41]. The receiving duct is a porous tube composed of one or more layers of epicuticle located in its extracellular space and bounded by microvilli. The collecting duct has an epithelial wall of flattened cells, lined by endocuticle, and a thin layer of epicuticle that is regularly folded into spiral ridges, annular arrays, or pointed peg-like projections, that reduce the volume of the lumen to control the free flow of secretion to the reservoir chamber $[35,39,41]$. The entrance of the collecting duct to the reservoir chamber is of great variability. It is located at the anterior or middle position in Scaritinae, Brachininae, and some Bembidiini, Pterostichini, Amarini, Carabini, Nebriini, Metriini, and Paussini $[33,35,39,40,42-44]$. While it is located near the entrance of the efferent duct in Harpalini, Agonini, Chlaeniini, Dryptini, Anthiini, Lebiini, Trachypachini, Omophronini, Loxandrini, Catapieseini, Galeritini, and Zuphini [31,33,35,45]. The reservoir chamber is a spherical, elongate, or bilobate compartment of variable size. Interwoven muscle bundles cover the outer wall and are connected to tracheal branches. The basal membrane supports flattened epithelial cells covered by a thin uniform layer of endo- and epicuticle. The muscular contraction regulates secretion through a valve that separates the reservoir from the reaction chamber. In Paussinae, Brachininae, and Carabinae, an accessory gland is located below the valve [35]. Secretions from the reservoir chamber are mixed with secretions from the accessory glands in the reaction chamber. The efferent duct leads from the reservoir chamber to the external orifice. The close association of the pygidial glands with the tracheal branches suggests a high aerobic metabolism.

The external orifice is located dorso-laterally in the posterior part of the abdomen, near to the antero-lateral margin of the ninth tergite, and close to the tergo-sternal suture in Carabinae, Scaritinae, Paussinae, Elaphrinae, Broscinae, and Brachinini, or at the posterolateral margin of the eighth tergite in derived lineages, e.g., Trechinae and Harpalinae, and including Licinini, Chlaeniini, Panagaeini, Anthiini, Zabrini, Oodini, Pterostichini, and Agonini [35,46]. Differences in pygidial gland morphology between sexes have been reported in Cicindela campestris [47]. 


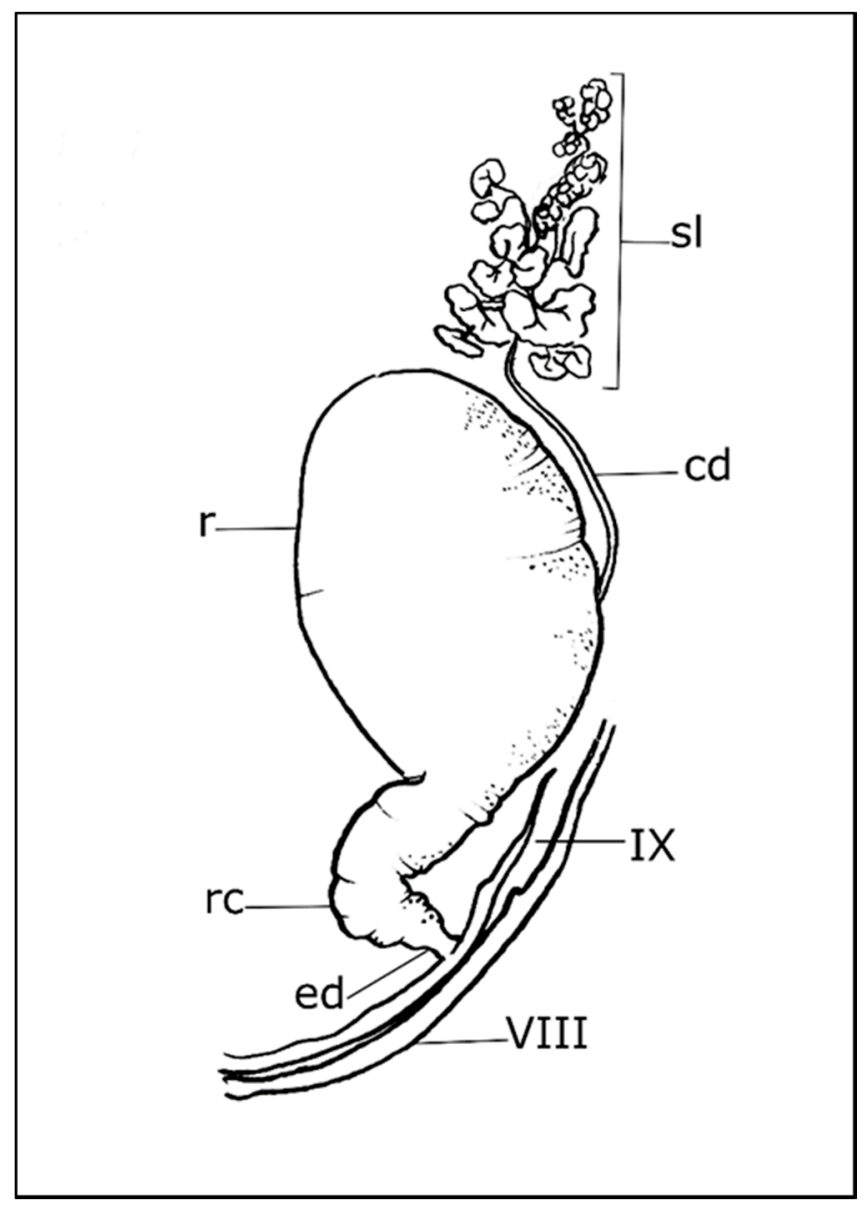

Figure 1. Schematic drawing of a pygidial gland. cd: collecting duct; ed: efferent duct; r: reservoir chamber; rc: reaction chamber; sl: secretory lobe; VIII: eighth tergite; IX: ninth tergite (for more details of species listed in the text, see Forsyth (1972) [35]).

Table 1. Summary of carabid species in which the pygidial gland morphology has been investigated and the method used for analyses. Abbreviations-CLSM: confocal laser scanning microscopy; FIB/SEM: focused ion beam/scanning electron microscopy; FM: fluorescence microscopy; LM: light microscopy; NLM: non linear microscopy; SEM: scanning electron microscopy; SR-PhC micro-CT: synchrotron radiation X-ray phase-contrast micro tomography.

\begin{tabular}{|c|c|c|c|c|c|}
\hline § Subfamily & Tribe & Genus & Species & Methodology & Refs \\
\hline \multirow[t]{6}{*}{ Paussinae } & Metriini & Metrius & M. contractus & LM; FIB/SEM & {$[35,39]$} \\
\hline & & Sinometrius & S.turnai & LM; FIB/SEM & [39] \\
\hline & Ozaeniini & Mystropomus & M. regularis & $\mathrm{LM}$ & [34] \\
\hline & Paussini & Paussus & P. favieri & LM; FM; FIB/SEM & {$[40]$} \\
\hline & & & P. laevifrons & LM & [35] \\
\hline & & Heteropaussus & H. jeanneli & LM & [35] \\
\hline \multirow[t]{2}{*}{ Cicindelinae } & Cicindelini & Cicindela & C. campestris & LM & [47] \\
\hline & & & C. hibrida & LM & [47] \\
\hline \multirow[t]{7}{*}{ Carabinae } & Carabini & Calosoma & C. oceanicum & LM & [34] \\
\hline & & & C. schayeri & LM & [34] \\
\hline & & & C. senegalense & LM & [35] \\
\hline & & & C. sycophanta & LM & [48] \\
\hline & & Carabus & C. (Tomocarabus) convexus & LM & [42] \\
\hline & & & C. (Procustes) coriaceus & LM & {$[42,49]$} \\
\hline & & & C. problematicus & LM & [35] \\
\hline
\end{tabular}


Table 1. Cont.

\begin{tabular}{|c|c|c|c|c|c|}
\hline § Subfamily & Tribe & Genus & Species & Methodology & Refs \\
\hline & & & C. ullrichii & LM & [49] \\
\hline & & & C. (Megodontus) violaceus & LM & [43] \\
\hline & Cychrini & Cychrus & C. caraboides rostratus & LM & [35] \\
\hline & Pamborini & Pamborus & P. alternans & LM & {$[34]$} \\
\hline \multirow[t]{2}{*}{ Elaphrinae } & Elaphrini & Elaphrus & E. cupreus & LM & [35] \\
\hline & & Blethisa & B. multipunctata & LM & [35] \\
\hline Loricerinae & Loricerini & Loricera & L. pilicornis & LM & {$[35]$} \\
\hline Omophroninae & Omophronini & Omophron & O. dentatum & LM & [35] \\
\hline \multirow[t]{5}{*}{ Nebriinae } & Nebriini & Eurynebria & E. complanata & LM & {$[35]$} \\
\hline & & Leistus & L. ferrugineus & LM & [35] \\
\hline & & Nebria & N. brevicollis & LM & [35] \\
\hline & & & N. psammodes & LM & [50] \\
\hline & Notiophilini & Notiophilus & N. substriatus & LM & {$[35]$} \\
\hline \multirow[t]{12}{*}{ Scaritinae } & Clivinini & Clivina & C. basalis & LM & [34] \\
\hline & & & C. collaris & LM & [35] \\
\hline & & & C. fossor & LM & [35] \\
\hline & & Schizogenius & S. lineolatus & LM & [31] \\
\hline & Dyschiriini & Dyschirius & D. globosus & LM & [35] \\
\hline & Pasimachini & Pasimachus & P. elongatus & LM & [35] \\
\hline & & & P. subsulcatus & LM & {$[51,52]$} \\
\hline & Carenini & Carenum & C. bonelli & LM & [34] \\
\hline & & & C. interruptum & LM & [34] \\
\hline & & & C. tinctillatum & LM & {$[34]$} \\
\hline & & Laccopterum & L. foveigerum & LM & [34] \\
\hline & & Philoscaphus & P. tuberculatus & LM & [34] \\
\hline \multirow[t]{3}{*}{ Broscinae } & Broscini & Eurylychnus & E. blagravei & LM & [34] \\
\hline & & & E. ollifi & LM & [34] \\
\hline & & Promecoderus & P. sp. & LM & [34] \\
\hline \multirow[t]{4}{*}{ Trechinae } & Trechini & Thalassotrechus & T. barbarae & LM & [35] \\
\hline & & Trechus & T. obtusus & LM & [35] \\
\hline & Bembidiini & Bembidion & B. lampros & LM & {$[28,35]$} \\
\hline & & & B. rupestre & LM & [35] \\
\hline \multirow[t]{3}{*}{ Patrobinae } & Patrobini & Amblytelus & A. curtus & LM & [34] \\
\hline & & Patrobus & P. longicornis & LM & [31] \\
\hline & & & P. septentrionis & LM & [35] \\
\hline \multirow[t]{21}{*}{ Harpalinae } & Morionini & Morion & M. simplex & LM & [31] \\
\hline & & Moriosomus & M. seticollis & LM & [31] \\
\hline & Perigonini & Diploharpus & D. laevissimo & LM & [31] \\
\hline & Loxandrini & Loxandrus & L. icarus & LM & [31] \\
\hline & & & L. longiformis & LM & [34] \\
\hline & & & L. velocipes & LM & [31] \\
\hline & & Oxycrepis & O. sp. & LM & [31] \\
\hline & Sphodrini & Calathus & C. ambiguus & LM & [35] \\
\hline & & Pristonychus & P. terricola & LM & [35] \\
\hline & Pterostichini & Abacomorphus & A. asperulus & LM & [34] \\
\hline & & Abaris & A. anaea & LM & [31] \\
\hline & & Blennidus & B. liodes & LM & [31] \\
\hline & & Castelnaudia & C. superba & LM & [34] \\
\hline & & Cratoferonia & C. phylarchus & LM & [34] \\
\hline & & Cratogaster & C. melas & LM & [34] \\
\hline & & Cyclotrachelus & C. sigillatus & LM & [31] \\
\hline & & Gasterllarius & G. honestus & LM & [31] \\
\hline & & Incastichus & I. aequidianus & LM & [31] \\
\hline & & Loxodactylus & L. carinulatus & LM & [34] \\
\hline & & Myas & M. coracinus & LM & [31] \\
\hline & & Notonomus & N. angusribasis & LM & [34] \\
\hline
\end{tabular}


Table 1. Cont.

\begin{tabular}{|c|c|c|c|c|c|}
\hline$\S$ Subfamily & Tribe & Genus & Species & Methodology & Refs \\
\hline & & & N. crenulatus & LM & [34] \\
\hline & & & N. miles & LM & [34] \\
\hline & & & N. muelleri & LM & [34] \\
\hline & & & N. opulentus & $\mathrm{LM}$ & [34] \\
\hline & & & N. rainbowi & $\mathrm{LM}$ & [34] \\
\hline & & & N. scotti & LM & {$[34]$} \\
\hline & & & N. triplogenioides & LM & [34] \\
\hline & & & N. variicollis & LM & [34] \\
\hline & & Prosopogmus & P. harpaloides & LM & [34] \\
\hline & & Pseudoceneus & P. iridescens & LM & [34] \\
\hline & & Pterostichus & P. (Cophosus) cylindricus & LM; NLM & [44] \\
\hline & & & P. (Monoferonia) diligendus & LM & [31] \\
\hline & & & P. externepunctatus roccai & $\mathrm{LM}$ & {$[50]$} \\
\hline & & & P. fortis & $\mathrm{LM}$ & [33] \\
\hline & & & P. luctuosus & $\mathrm{LM}$ & {$[31]$} \\
\hline & & & P. madidus & $\mathrm{LM}$ & [38] \\
\hline & & & P. melanarius & LM & [35] \\
\hline & & & P. melas & $\begin{array}{c}\text { SR-PHC } \\
\text { MICRO-CT }\end{array}$ & [53] \\
\hline & & & P. (Pseudomaseus) nigrita & LM; NLM & [44] \\
\hline & & Rhytisternus & R. laevilaterus & LM & [34] \\
\hline & & Sarticus & S. cyaneocinctus & $\mathrm{LM}$ & {$[34]$} \\
\hline & & Sphodrosomus & S. saisseri & $\mathrm{LM}$ & [34] \\
\hline & & Trichosternus & T. nudipes & LM & {$[34]$} \\
\hline & Platynini & Agonum & A. dorsale & $\mathrm{LM}$ & [35] \\
\hline \multirow{3}{*}{\multicolumn{2}{|c|}{ Zabrini }} & Amara & A. aenea & $\mathrm{LM}$ & [35] \\
\hline & & Curtonotus & C. fulvus & $\mathrm{LM}$ & [35] \\
\hline & & Zabrus & Z. tenebriodes & LM & [35] \\
\hline \multirow{2}{*}{\multicolumn{2}{|c|}{ Molopini }} & Abax & A. parallelepipedus (sub:A. ater) & LM & {$[35,49]$} \\
\hline & & Molops & M. (Stenochoromus)montenegrinus & LM; NLM & {$[44]$} \\
\hline \multirow{5}{*}{\multicolumn{2}{|c|}{ Harpalini }} & Bradycellus & B. harpalinus & LM & [35] \\
\hline & & Diaphoromerus & D. edwardsi & $\mathrm{LM}$ & [34] \\
\hline & & & H. aeneus & LM & {$[35]$} \\
\hline & & Harpalus & H. pensylvanicus & CLSM & [54] \\
\hline & & Pseudophonus & P. rufipes (sub:pubescens) & LM & {$[35]$} \\
\hline \multirow{5}{*}{\multicolumn{2}{|c|}{ Licinini }} & Badister & B. bipustulatus & LM & [35] \\
\hline & & Dicrochile & D. brevicollis & LM & [34] \\
\hline & & & D. goryi & LM & [34] \\
\hline & & Licinus & L. depressus & $\mathrm{LM}$ & [35] \\
\hline & & Syagonix & S. blackburni & $\mathrm{LM}$ & {$[34]$} \\
\hline \multirow{8}{*}{\multicolumn{2}{|c|}{ Chlaeniini }} & Chlaenius & C. australis & LM & [34] \\
\hline & & & C. cumatilis & $\mathrm{LM}$ & [35] \\
\hline & & & C. inops & LM & [33] \\
\hline & & & C. pallipes & LM & [33] \\
\hline & & & C. velutinus & LM & [50] \\
\hline & & & C. vestitus & LM & {$[35,50]$} \\
\hline & & Oodes & O. amaroides & LM & [31] \\
\hline & & & O. hehpioides & $\mathrm{LM}$ & [35] \\
\hline \multirow{4}{*}{\multicolumn{2}{|c|}{ Panagaenini }} & Craspedophorus & C. sp. & $\mathrm{LM}$ & {$[34]$} \\
\hline & & Panagaeus & P. crux-major & $\mathrm{LM}$ & [35] \\
\hline & & Psecadius & P. eustalactus & $\mathrm{LM}$ & [35] \\
\hline & & Tefflus & T. sp. & LM & [35] \\
\hline \multirow{3}{*}{\multicolumn{2}{|c|}{$\begin{array}{l}\text { Masoreini } \\
\text { Odacanthini }\end{array}$}} & Masoreus & M. wetterhlii & LM & [35] \\
\hline & & Colliuris & C. melanura & LM & [35] \\
\hline & & & C. pensylvanica & LM & [31] \\
\hline
\end{tabular}


Table 1. Cont.

\begin{tabular}{|c|c|c|c|c|c|}
\hline$\S$ Subfamily & Tribe & Genus & Species & Methodology & Refs \\
\hline & Lebiini & Eudalia & E. macleayi & LM & [34] \\
\hline & & Metabletus & M. foveatus & LM & [35] \\
\hline & & Movmolyce & M. phyllodes & LM & [35] \\
\hline & Galeritini & Galerita & G. lecontei & LM & [45] \\
\hline & Anthiini & Anthia & A. artemis & LM & [35] \\
\hline & Helluonini & Helluo & H. costatus & LM & [34] \\
\hline & Dercylini & Dercylus (s.s.) & D. sp. & LM & [31] \\
\hline & Catapieseini & Catapiesis & C. attenuata & LM & [31] \\
\hline & & & C. sulcipennis & LM & [31] \\
\hline & Dryptini & Drypta & D. dentata & LM & [35] \\
\hline & & & D. japonica & LM & [33] \\
\hline & Pseudomorphini & Sphallomorpha & S. colymbeioides & LM & [34] \\
\hline \multirow[t]{13}{*}{ Brachininae } & Brachinini & Aptinus & A. bombarda & LM; FM; FIB/SEM & [41] \\
\hline & & & A. crepitus & LM; FM; FIB/SEM & [41] \\
\hline & & & A. displosor & LM & [35] \\
\hline & & Brachinus & B. crepitans & LM & [35] \\
\hline & & & B. elongatus & $\begin{array}{l}\text { LM; FM; FIB/SEM; } \\
\text { SEM }\end{array}$ & {$[41,55]$} \\
\hline & & & B. sclopeta & LM; FM; FIB/SEM & [41] \\
\hline & & & B. stenoderus & LM & [33] \\
\hline & & & P. verticalis & LM & [34] \\
\hline & & Pheropsophus & P. africanus & LM; FM; FIB/SEM & {$[41]$} \\
\hline & & & P. hispanus & LM; FM; FIB/SEM & [41] \\
\hline & & & P. lissoderus & LM & [35] \\
\hline & & & P. occipitalis & LM; FM; FIB/SEM & [41] \\
\hline & & & P. verticalis & LM & [34] \\
\hline
\end{tabular}

$\S$ Classification of taxa has been arranged according to Bousquet [56] and Beutel and Ribera [57].

\section{Excretory Mechanisms}

Oozing, spraying, and crepitation are the main types of external excretory mechanisms observed in carabid beetles in response to disturbance [58]. Oozing of secretion over the cuticle of the hind segments occurs in species that have relatively weakly developed muscles on the wall of the reservoir chamber, i.e., in the tribes Nebriini, Notiophilini, Loricerini, Elaphrini, and the subfamilies Scaritinae, Cicindelinae, and Broscinae [32,35]. This is probably the plesiomorphic mode of discharge, whereas the secretion expelled by strong muscle pressure on the reservoirs is an apomorphic adaptation. The discharge of a directional secretion by turning the tip of the abdomen has been observed in many taxa that exhibit a variable secretion discharge, such as Trechini, Bembidiini, Galeritini, Carabini, Cychrini, Harpalini, Agonini, Anthiini, and Pterostichini (except the genus Abax) $[32,45,59]$. Bombardier beetles discharge secretion by crepitation [60,61], with the exception of Metrius contractus, which discharges its secretion using the oozing ancestral discharge mechanism [39,62]. This discharge has evolved independently in Ozaenini and Paussini on the one hand and in Brachinini on the other. In the tribe Brachinini, the explosive defence is an active enzymatic exothermic reaction that produces benzoquinones, free oxygen, water, and heat up to $100{ }^{\circ} \mathrm{C}$ [55]. The process begins with muscle contraction of the reservoir chamber, which allows stored hydroquinones and hydrogen peroxide, to move through the one-way valve, enter the reaction chamber, and mix with catalases and peroxidases produced by the accessory glands. In Paussinae, fluids are directed via a cuticular fold (Coanda flange) located at the posterolateral angle of the elytra, which serves as a launching guide for rapid anterior discharge $[60,61,63]$. The ability to direct the sprayed secretion has also been observed in Calosoma prominens [64]. 


\section{Chemical Compounds of Secretion}

To date, over 363 species from 45 tribes have been studied by gas chromatographymass spectrometry (GC-MS) (Table 2) in dichloromethane or hexane extracts. The semiochemicals, listed in Table 2, belong to one of the following classes: aliphatic and aromatic carboxylic acids, phenols (m-cresol and xylenol), aldehydes, quinones, hydrocarbons, ketones, terpenes, and esters. The biosynthetic pathways of these compounds have been extensively studied in arthropods [27,65]. However, studies addressing their biogenesis in the pygidial gland of carabids are lacking. The enzymatic derivation of quinones is one of the few metabolic pathways investigated. The bombardier beetle Brachinus elongatulus has the ability to convert m-cresol to 2-methyl-1,4-hydroquinone, which is then oxidised to 2-methyl-1,4-benzoquinone (toluquinone), within $24 \mathrm{~h}$ in its defensive spray, when added to food or injected into the haemocoel [66]. An origin from amino acids has been demonstrated for carboxylic acids. Valine is converted into methacrylic and isobutyric acids in Carabus taedatus [67] and Scarites subterraneus [68]. Biosynthesis of both tiglic and ethacrylic acid from isoleucine via 2-methylbutyric acid has been demonstrated in Pterostichus californicus [69]. Indeed, valine and isoleucine are essential amino acids, diet-dependent and strictly regulated by the availability of resources [70].

\subsection{Interspecific Adaptations}

The chemical composition of pygidial gland secretions exhibits interspecific variability within and among subfamilies (Table 2). This variability is the result of a trade-off between the diversity of predators in different habitats and the fitness costs of resource allocation in life traits such as behavioural defences against these enemies [2,71].

The chemicals found in secretions belong to two different functional categories, allomones and bacteriostats. Allomones are primarily involved in the secondary antipredator responses that carabids exhibit as prey to actively defend themselves against predators. Ground beetles emit volatile substances directed at specific groups of arthropods or vertebrates that act as repellents on the chemoreception of predators or interfere with physiological processes as irritants (emesis, vesication) [58]. Deterrent, toxic, and irritant properties of pygidial gland secretions are known in bombardier beetles (Brachinini), which release irritant quinones by a hot, pulsed spray mechanism $[55,61,66]$ as an antipredator defence [72,73]. Quinones are the main class of compounds also found in the secretions of obligate or facultative myrmecophilous species belonging to Metrini, Ozaenini, and Paussini [34,74]. In the defensive secretions of Clivinini [75] and Metrius contractus [62], they are associated with complex mixtures of monoterpenes or hydrocarbons (Table 2). Saturated and unsaturated aliphatic carboxylic acids and fatty acids are widely distributed in the subfamilies Carabinae, Loricerinae, Nebrinae, Scaritinae, Scaritinae, and Harpalinae. They are recorded as a separate compound class in some species that belong to the tribes Pamborini, Elaphrini, Loricerini, Omophronini, Notiophilini, Broscini, Patrobini, Sphodrini, Pterostichini, Platynini, Harpalini, Licinini, and Lebiini. In Cychrini, irritant carboxylic acids (i.e., methacrylic acid) and fatty acids (i.e., tiglic acid) are released, associated with a stridulatory elytra-abdominal mechanism acting as an acoustic warning signal against predators [76,77]. Behavioural analyses showed that Pasimachus subsulcatus (Scaritinae) secretes a mixture of methacrylic acid and fatty acids to protect itself from lizards [51,52]. Carboxylic acids are also found in variable associations with terpenes, quinones, and hydrocarbons in Trechinae, and Harpalinae (Table 2). The repellent effect of salicylaldehyde in the secretion of Calosoma prominens has been tested against ants and vertebrates [64]. This chemical has also been detected in C. sycophanta, C. schayeri, C. oceanicum [34,48], C. prominens [64], C. chinenses [33], Loxandrus longiformis [34], and Bembidion quadriguttatum, A. flavipes [78] in a mixture with carboxylic acids. Benzaldehyde is the typical component of secretion in Cicindelinae $[79,80]$. It is produced via a cyanogenetic pathway that is absent in the other carabid subfamilies [81]. In tiger beetles, secretion of benzaldehyde may be associated with several antipredator characters, including aposematic camouflage, flight, and gregarious behaviour to avoid predators such as robber flies, lizards, and birds $[17,82,83]$. 
Synergism between polar volatile irritant compounds and lipophilic components of secretion has been demonstrated. Nonpolar lipophilic components from Galerita lecontei (long-chain hydrocarbons and esters) act as wetting and penetration enhancers and facilitate the spread of volatile polar compounds such as formic and acetic acids in the cuticle of predators [45]. In Helluomorphoides clairvillei, n-nonyl acetate facilitates the spread of formic acid through the epidermis or cuticle of predators [84]. The same surfactant effect has been attributed to hydrocarbons [85] for the uptake of repellent quinones in Metrius contractus [62].

The mixture of substances in glandular secretions also has biological functions. In vitro assays have shown that the pygidial gland secretion inhibits cell proliferation [86]. The mixture of aromatic (benzoic acid) and aliphatic carboxylic acids, esters, and terpenes have antimicrobial and fungicidal activity in Carabus ullrichii, C. coriaceus, Abax parallelepipedus [49], caterpillar hunter Calosoma sycophanta [48], and troglophilic and guanophilic Laemostenus (Pristonychus) punctatus [87]. Complex mixtures of monoterpenes are found in the defensive secretions of a large number of the species reported here (Table 2). Terpenes are volatile and are present in glandular secretions of many taxa, acting as chemical deterrents, trail scents, mating attractants, or alarm pheromones [22]. In carabid beetles, they have also been detected in the pupal stages of Carabus lefebvrei [88].

\subsection{Intraspecific Adaptations}

Little is known about intraspecific variation in secretion as a function of sex, age, and resource availability. Nevertheless, data collected to date suggest that chemical secretion plays a parsimonious role in both antipredation and mating behaviour. In Oodes americanus, defensive secretion shows qualitative differences in males and females [89]. The sexual dimorphism of carboxylic acids found in the defensive secretion of Chlaenius cordicollis depends on the reproductive status and age of both sexes and provides a means of chemical communication between the sexes [89,90]. Sex-specific variation likely protects mates during copulation, and the flower number of compounds in female secretions saves females the cost of synthesising them [90]. Although compounds that act as pheromones, such as pentacosadiene, 7-hexyldocosane, 9-methyltetracosane, have been detected in Laemostenus punctatus, Trachypachus gibbsi, and Helluomorphoides clairvillei, studies on their role in alarm or sex-aggregation reproductive behaviour are limited [27].

Intra- and inter-population variation in defensive secretion has also been documented to reflect genetic variability at the population level in responses to selective habitat pressure, as observed in Chaenius cordicollis [91], Pasimachus subsulcatus [51], and Cicindelinae [80]. On the other hand, the shift in secretion composition may have a dietary origin, as observed in species of the genus Scaphinotus [77]. These findings suggest the role of dietary chemical precursors in the biosynthesis of chemical secretions. 
Table 2. Components of pygidial gland secretions in Carabidae. Classification of taxa has been arranged according to Bousquet [56] and Beutel and Ribera [57].

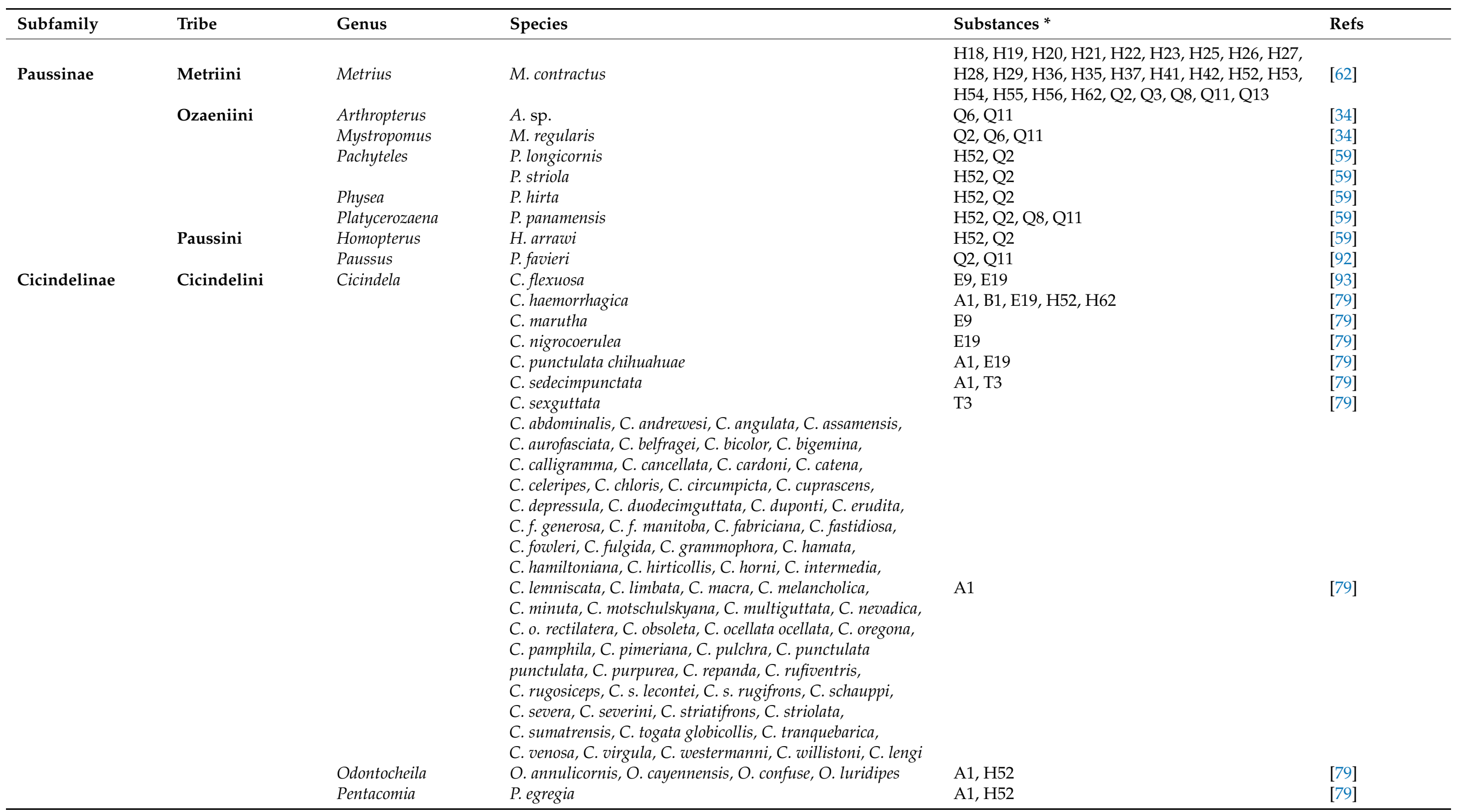


Table 2. Cont.

\begin{tabular}{|c|c|c|c|c|c|}
\hline Subfamily & Tribe & Genus & Species & Substances * & Refs \\
\hline \multirow[t]{3}{*}{ Cicindelinae } & Collyridini & Neocollyris & N. variitarsus & A1 & [79] \\
\hline & Megacephalini & Megacephala & M. carolina & $\mathrm{A} 1, \mathrm{~B} 8, \mathrm{~N} 1$ & [79] \\
\hline & & Omus & O. audouini & B15 & [79] \\
\hline \multirow[t]{27}{*}{ Carabinae } & Carabini & Calosoma & C. (Campalita) chinense & $\mathrm{C} 4, \mathrm{~F} 27, \mathrm{~A} 2$ & [33] \\
\hline & & & C. externuum & $\mathrm{C} 4$ & {$[28]$} \\
\hline & & & C. marginalis & $\mathrm{C} 4$ & {$[28]$} \\
\hline & & & C. oceanicum & $\mathrm{A} 2, \mathrm{C} 4, \mathrm{~F} 5$ & [34] \\
\hline & & & C. prominens & A2 & {$[30,64]$} \\
\hline & & & C. sycophanta & $\mathrm{A} 2, \mathrm{C} 4, \mathrm{C} 5, \mathrm{~B} 1, \mathrm{~F} 2, \mathrm{~F} 6, \mathrm{~F} 11, \mathrm{~F} 17, \mathrm{~F} 25, \mathrm{~F} 27$ & {$[30,48]$} \\
\hline & & Carabus & C. auratus & $\mathrm{C} 4, \mathrm{~F} 27$ & {$[28,30,78,94]$} \\
\hline & & & C. auronitens & $\mathrm{C} 4, \mathrm{~F} 27$ & {$[30,78,94,95]$} \\
\hline & & & C. (Damastes) blaptoides & $\mathrm{C} 2, \mathrm{C} 4, \mathrm{~F} 27$ & [33] \\
\hline & & & C. (Megodontus) caelatus & B1, C1, C4, F1, F2, F8, F11, F17, F25, F27 & [43] \\
\hline & & & C. (Tachypus) cancellatus & $\mathrm{C} 4, \mathrm{~F} 27$ & [30] \\
\hline & & & C. cansellatus & $\mathrm{C} 4, \mathrm{~F} 27$ & {$[78]$} \\
\hline & & & C. cyaneus & $\mathrm{C} 4, \mathrm{~F} 27$ & {$[30]$} \\
\hline & & & C. (Tomogarabus) convexus & $\mathrm{B} 1, \mathrm{C} 4, \mathrm{~F} 27$ & {$[30,42,78,94]$} \\
\hline & & & C. granulatus & $\mathrm{C} 4, \mathrm{~F} 27$ & {$[30,78,94]$} \\
\hline & & & C. intricatus & $\mathrm{C} 4, \mathrm{~F} 27$ & [94] \\
\hline & & & C. (Platycarabus) irregularis & $\mathrm{C} 4, \mathrm{~F} 27$ & {$[30,94]$} \\
\hline & & & C. (Apotomopterus) japonicus & $\mathrm{C} 2, \mathrm{C} 4, \mathrm{~F} 27$ & [33] \\
\hline & & & C. (Archicarabus) montivagus & $\mathrm{C} 4, \mathrm{~F} 27$ & [43] \\
\hline & & & C. porrecticollis & $\mathrm{C} 2, \mathrm{C} 4, \mathrm{~F} 27$ & [33] \\
\hline & & & C. problematicus & $\mathrm{C} 4, \mathrm{~F} 27$ & {$[28,78]$} \\
\hline & & & C. procelus & $\mathrm{C} 2, \mathrm{C} 4, \mathrm{~F} 27$ & {$[30,33]$} \\
\hline & & & C. taedutus & $\mathrm{C} 2, \mathrm{C} 4$ & [67] \\
\hline & & & C. ullrichii & $\mathrm{B} 1, \mathrm{C} 4, \mathrm{~F} 1, \mathrm{~F} 2, \mathrm{~F} 11, \mathrm{~F} 17, \mathrm{~F} 27$ & {$[30,49,94]$} \\
\hline & & & C. (M.) violaceus & B1, C4, F1, F11, F17, F25, F27 & {$[30,43,94]$} \\
\hline & & & C. (Apotomopterus) yaconinus & $\mathrm{C} 2, \mathrm{C} 4, \mathrm{~F} 27$ & [33] \\
\hline & & Hemicarabus & H. tuberculosus & $\mathrm{C} 2, \mathrm{C} 4$ & [33] \\
\hline
\end{tabular}


Table 2. Cont.

\begin{tabular}{|c|c|c|c|c|c|}
\hline Subfamily & Tribe & Genus & Species & Substances * & Refs \\
\hline \multirow[t]{6}{*}{ Carabinae } & Ceroglossini & Ceroglossus & C. buqueti & $\mathrm{B} 1, \mathrm{C} 1, \mathrm{C} 2, \mathrm{C} 4, \mathrm{C} 5, \mathrm{~F} 3, \mathrm{~F} 11, \mathrm{~F} 14, \mathrm{~F} 27, \mathrm{H} 61, \mathrm{~S} 1$ & [96] \\
\hline & & & C. chilensis & $\mathrm{B} 1, \mathrm{C} 2, \mathrm{C} 4, \mathrm{~F} 3, \mathrm{~F} 11, \mathrm{~F} 14, \mathrm{~F} 27, \mathrm{H} 61$ & [96] \\
\hline & & & C. magellanicus & $\mathrm{B} 1, \mathrm{C} 2, \mathrm{C} 4, \mathrm{~F} 3, \mathrm{~F} 11, \mathrm{~S} 1$ & [96] \\
\hline & Cychrini & Cychrus & C. caraboides rostratus & $\mathrm{C} 4, \mathrm{~F} 27$ & {$[28,30,94]$} \\
\hline & & Scaphinotus & S. andrewsi germari, S. andrewsi montana, S. virdus, S. webbi & $\mathrm{C} 4, \mathrm{~F} 27$ & [77] \\
\hline & Pamborini & Pamborus & P. alternans, $P$. guerini, $P$. pradieri, $P$. viridis & $\mathrm{C} 2, \mathrm{C} 4$ & {$[34]$} \\
\hline Elaphrinae & Elaphrini & Elaphrus & E. riparius & F11, F14 & {$[28]$} \\
\hline Loricerinae & Loricerini & Loricera & L. pilicornis & F11, F14 & [28] \\
\hline Omophroninae & Omophronini & Omophron & O. limbatum & F11, F14 & [28] \\
\hline \multirow[t]{6}{*}{ Nebriinae } & Nebriini & Leistus & L. ferrugineus & $\mathrm{C} 4, \mathrm{~F} 27$ & {$[28,78]$} \\
\hline & & Nebria & N. chinensis & $\mathrm{C} 2, \mathrm{C} 4, \mathrm{~F} 27$ & [33] \\
\hline & & & N. lewisi & $\mathrm{C} 2, \mathrm{C} 4, \mathrm{~F} 27$ & [33] \\
\hline & & & N. livida & $\mathrm{C} 4, \mathrm{~F} 27$ & {$[28,78]$} \\
\hline & & & N. macrogona & $\mathrm{C} 2, \mathrm{C} 4, \mathrm{~F} 27$ & [33] \\
\hline & & & N. psammodes & $\mathrm{C} 4, \mathrm{~F} 27$ & {$[50]$} \\
\hline \multirow[t]{2}{*}{ Nebriinae } & Notiophilini & Notiophilus & N. biguttatus & F11, F14 & [28] \\
\hline & & & N. impressifrons & $\mathrm{C} 4, \mathrm{~F} 27$ & {$[33]$} \\
\hline \multirow[t]{15}{*}{ Scaritinae } & Scaritini & Scarites & S. aterrimus & $\mathrm{C} 4, \mathrm{~F} 1, \mathrm{~F} 6, \mathrm{~F} 13, \mathrm{~F} 27$ & [33] \\
\hline & & & S. sulcatus & C4, F1, F13, F27 & {$[33]$} \\
\hline & & & S. terricola & C4, F1, F13, F27 & {$[33]$} \\
\hline & Clivinini & Ardistomis & A. schaumii & $\mathrm{Q} 11, \mathrm{~T} 1, \mathrm{~T} 4$ & {$[75]$} \\
\hline & & Clivina & C. basalis & Q1, Q11 & [34] \\
\hline & & & C. fossor & $\mathrm{Q} 1, \mathrm{Q} 6, \mathrm{Q} 2, \mathrm{Q} 11, \mathrm{Q} 12, \mathrm{Q} 13$ & {$[78]$} \\
\hline & & Semiardistomis & S. puncticollis & $\mathrm{Q} 2, \mathrm{Q} 11, \mathrm{~T} 2, \mathrm{~T} 4, \mathrm{~T} 5, \mathrm{~T} 6, \mathrm{~T} 7$ & [75] \\
\hline & & Schizogenius & S. lineolatus & F8, F9, F10 & [31] \\
\hline & Dyschiriini & Dyschirius & D. wilsoni & $\mathrm{B} 9, \mathrm{~K} 2, \mathrm{~K} 7, \mathrm{~T} 3$ & {$[97]$} \\
\hline & Pasimachini & Pasimachus & P. subsulcatus & C4, F1, F11, F14, F17, F25, F27 & {$[51,52]$} \\
\hline & Carenini & Carenum & C. bonelli & $\mathrm{C} 4, \mathrm{~F} 1, \mathrm{~F} 7, \mathrm{~F} 13$ & {$[34]$} \\
\hline & & & C. interruptum & $\mathrm{C} 4, \mathrm{~F} 1, \mathrm{~F} 13$ & [34] \\
\hline & & & C. tinctillatum & $\mathrm{C} 4, \mathrm{~F} 1, \mathrm{~F} 13, \mathrm{~F} 27$ & [34] \\
\hline & & Laccopterum & L. foveigerum & $\mathrm{C} 2, \mathrm{C} 4, \mathrm{~F} 5, \mathrm{~F} 6, \mathrm{~F} 7, \mathrm{~F} 13, \mathrm{~F} 27$ & [34] \\
\hline & & Philoscaphus & P. tuberculatus & C4, F6, F12, F13, F27 & {$[34]$} \\
\hline Broscinae & Broscini & Broscosoma & B. doenitzi & F2, F14 & {$[33]$} \\
\hline
\end{tabular}


Table 2. Cont.

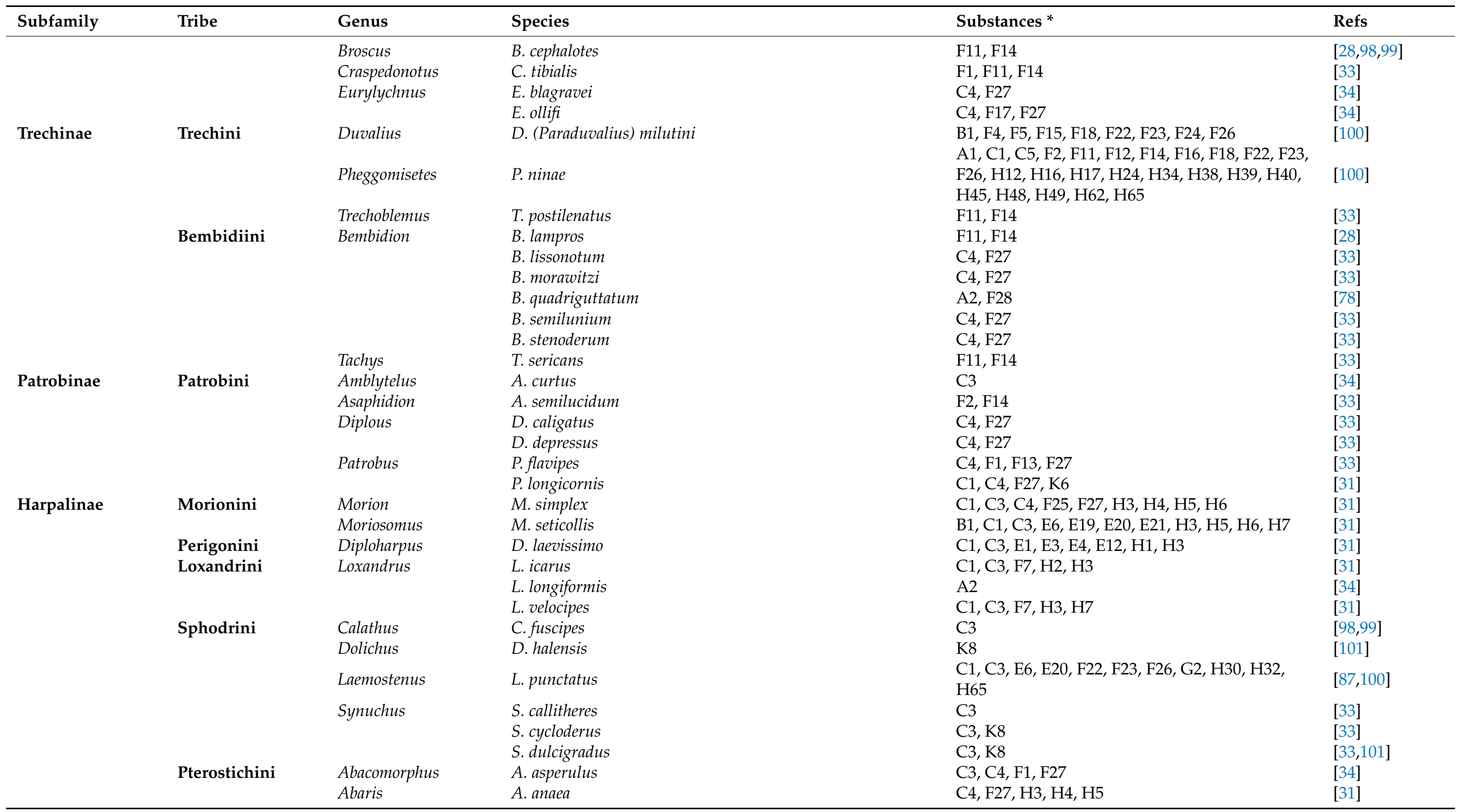


Table 2. Cont

\begin{tabular}{|c|c|c|c|c|c|}
\hline Subfamily & Tribe & Genus & Species & Substances * & Refs \\
\hline & & Blennidus & B. liodes & C4, F14, F27, H4 & [31] \\
\hline & & Castelnaudia & C. superba & $\mathrm{C} 1, \mathrm{C} 4, \mathrm{~F} 27$ & {$[34]$} \\
\hline & & Cratoferonia & C. phylarchus & $\mathrm{C} 4, \mathrm{~F} 27$ & {$[34]$} \\
\hline & & Cratogaster & C. melas & $\mathrm{C} 4, \mathrm{~F} 27$ & {$[34]$} \\
\hline & & Cyclotrachelus & C. sigillatus & $\mathrm{C} 1, \mathrm{C} 3$ & {$[31]$} \\
\hline & & Gasterllarius & G. honestus & $\mathrm{C} 4, \mathrm{~F} 25$ & {$[31]$} \\
\hline & & Incastichus & I. aequidianus & $\mathrm{C} 1, \mathrm{C} 3$ & {$[31]$} \\
\hline & & Lesticus & L. magnus & $\mathrm{C} 4, \mathrm{~F} 27$ & [33] \\
\hline & & Myas & M. coracinus & $\mathrm{C} 4, \mathrm{~F} 25, \mathrm{~F} 27$ & [31] \\
\hline & & Notonomus & $\begin{array}{l}\text { N. angustibasis, N. crenulatus, N. miles, N. muelleri, } N \text {. } \\
\text { opulentus, N. rainbowi, N. scotti, N. triplogenioides, } N . \\
\text { variicollis }\end{array}$ & $\mathrm{C} 3$ & [34] \\
\hline & & Poecilus & P. coerulescens & C4, F27 & {$[33]$} \\
\hline & & & P. cupreus & C4, F27, H8, H62, H65 & [78] \\
\hline & & & P. fortipes & $\mathrm{C} 4, \mathrm{~F} 27$ & [33] \\
\hline & & Prosopogmus & P. harpaloides & $\mathrm{C} 4$ & {$[34]$} \\
\hline & & Pseudoceneus & P. iridescens & $\mathrm{C} 4, \mathrm{~F} 27$ & {$[34]$} \\
\hline & & & P. daisenicus & $\mathrm{C} 2, \mathrm{C} 4, \mathrm{~F} 27$ & [33] \\
\hline & & & P. (Monoferonia) diligendus & $\mathrm{C} 4, \mathrm{~F} 27$ & {$[31]$} \\
\hline & & & P. externepunctatus roccai & C4, F11, F27, H62, H65 & {$[50]$} \\
\hline & & & P. fortis & $\mathrm{C} 2, \mathrm{C} 4, \mathrm{~F} 27$ & [33] \\
\hline & & & P. fujimurai & $\mathrm{C} 2, \mathrm{C} 4, \mathrm{~F} 27$ & [33] \\
\hline & & & P. longinquus & $\mathrm{C} 2, \mathrm{C} 4, \mathrm{~F} 27$ & [33] \\
\hline & & & P. luctuosus & $\mathrm{C} 4, \mathrm{~F} 27$ & {$[31]$} \\
\hline & & & P. macer & C4, F27, H8, H62, H65 & {$[28,78]$} \\
\hline & & & P. masidai & $\mathrm{C} 2, \mathrm{C} 4, \mathrm{~F} 27$ & [33] \\
\hline & & & P. (Ferodinius) melas & C4, F11, F17, F25, F27, H8, H62, H65 & {$[28,44,78]$} \\
\hline & & & P. metallicus & $\mathrm{C} 4, \mathrm{~F} 27, \mathrm{H} 8, \mathrm{H} 62, \mathrm{H} 65$ & {$[28,30,78,94]$} \\
\hline & & & P. microcephalus & $\mathrm{C} 2, \mathrm{C} 4, \mathrm{~F} 27$ & [33] \\
\hline & & & P. niger & C4, F27, H8, H62, H65 & {$[28,30,78,94]$} \\
\hline & & & P. (Pseudomaseus) nigrita & $\begin{array}{l}\text { C1, C4, C5, F9, F11, F17, F27, H13, H14, H15, } \\
\text { H57, H60, H62, H64, H65 }\end{array}$ & [44] \\
\hline & & & P. prolongatus & $\mathrm{C} 2, \mathrm{C} 4, \mathrm{~F} 27$ & [33] \\
\hline & & & P. rotundangulus & $\mathrm{C} 2, \mathrm{C} 4, \mathrm{~F} 27$ & {$[33]$} \\
\hline
\end{tabular}


Table 2. Cont.

\begin{tabular}{|c|c|c|c|c|c|}
\hline Subfamily & Tribe & Genus & Species & Substances * & Refs \\
\hline & \multirow{17}{*}{ Platynini } & & P. vulgaris & C4, F27, H8, H62, H65 & {$[30,78,94]$} \\
\hline & & Rhytisternus & R. laevilaterus & $\mathrm{C} 4, \mathrm{~F} 27$ & [34] \\
\hline & & Sarticus & S. cyaneocinctus & $\mathrm{C} 3$ & [34] \\
\hline & & Sphodrosomus & S. saisseri & C3 & [34] \\
\hline & & Trichosternus & T. nudipes & $\mathrm{C} 4, \mathrm{~F} 27$ & {$[34]$} \\
\hline & & Trigonotoma & T. lewisii & $\mathrm{C} 4, \mathrm{~F} 27$ & [33] \\
\hline & & Trigonognatha & T. cuprescens & C4, F27 & [33] \\
\hline & & Agonum & A. chalcomum & $\mathrm{C} 3, \mathrm{~K} 8$ & {$[33,101]$} \\
\hline & & \multirow[t]{2}{*}{ Anchomenus } & A. (Idiochroma) dorsalis & H14, H58, H60, H65 & [28] \\
\hline & & & A. leucopus & $\mathrm{C} 3$ & [33] \\
\hline & & \multirow[t]{2}{*}{ Colpodes } & C. atricomes & $\mathrm{C} 3$ & [33] \\
\hline & & & C. japonicus & $\mathrm{C} 3$ & [33] \\
\hline & & Loxocrepis & L. rubriola & $\mathrm{C} 3$ & [33] \\
\hline & & Lorostemma & L. ogurae & $\mathrm{C} 3$ & {$[33]$} \\
\hline & & Platynus & P. brunneomarginatus & C3, F18, F23, H52, H62, H65, K1, K3, K6, K8 & {$[31]$} \\
\hline & & & P. magnus & C3 & [33] \\
\hline & & & P. ovipennis & C3, F19, H52, H62, H65, K1, K3, K6, K8 & {$[102]$} \\
\hline & \multirow{5}{*}{ Zabrini } & \multirow{3}{*}{ Amara } & A. chalcophaea & $\mathrm{C} 2, \mathrm{C} 4, \mathrm{~F} 1, \mathrm{~F} 27$ & {$[33]$} \\
\hline & & & A. familiaris & C4, F27, H8, H62, H65 & {$[28,78]$} \\
\hline & & & A. similata & $\mathrm{C} 4, \mathrm{~F} 27, \mathrm{H} 8, \mathrm{H} 62, \mathrm{H} 65$ & {$[28,78]$} \\
\hline & & Bradytus & B. ampliatus, B. simplicidens & $\mathrm{C} 2, \mathrm{C} 4, \mathrm{~F} 1, \mathrm{~F} 27$ & [33] \\
\hline & & Curtonotus & C. giganteus & $\mathrm{C} 2, \mathrm{C} 4, \mathrm{~F} 1, \mathrm{~F} 27$ & [33] \\
\hline & \multirow[t]{5}{*}{ Molopini } & \multirow[t]{3}{*}{ Abax } & A. ovalis & $\mathrm{C} 4, \mathrm{~F} 27$ & {$[28,30,78]$} \\
\hline & & & A. parallelepipedus (sub:A. ater) & C4, C5, F6, F11, F25, F27 & {$[28,30,49,78]$} \\
\hline & & & A. parallelus & C4, F27 & {$[30,78,95]$} \\
\hline & & Molops & M. elatus & $\mathrm{C} 4, \mathrm{~F} 27$ & {$[28,78]$} \\
\hline & & & M. (Stenochoromus) montenegrinus & $\mathrm{C} 1, \mathrm{C} 4, \mathrm{C} 5, \mathrm{~F} 1, \mathrm{~F} 2, \mathrm{~F} 5, \mathrm{~F} 8, \mathrm{~F} 9, \mathrm{~F} 11, \mathrm{~F} 17, \mathrm{~F} 28$ & [44] \\
\hline & \multirow[t]{7}{*}{ Harpalini } & \multirow[t]{2}{*}{ Anisodactylus } & A. signatus & $\mathrm{C} 3, \mathrm{~K} 8$ & {$[33,101]$} \\
\hline & & & A. tricuspidatus & $\mathrm{C} 3$ & {$[33]$} \\
\hline & & Anoplogenius & A. cyanescens & $\mathrm{C} 3$ & [33] \\
\hline & & Bradycellus & B. inornatus & $\mathrm{C} 3$ & [33] \\
\hline & & Diaphoromerus & D. edwardsi & $\mathrm{C} 3$ & [34] \\
\hline & & Harpalus & H. atratus & $\mathrm{C} 3$ & {$[98,99]$} \\
\hline & & & H. capito & $\mathrm{C} 3, \mathrm{~K} 8$ & {$[33,101]$} \\
\hline
\end{tabular}


Table 2. Cont

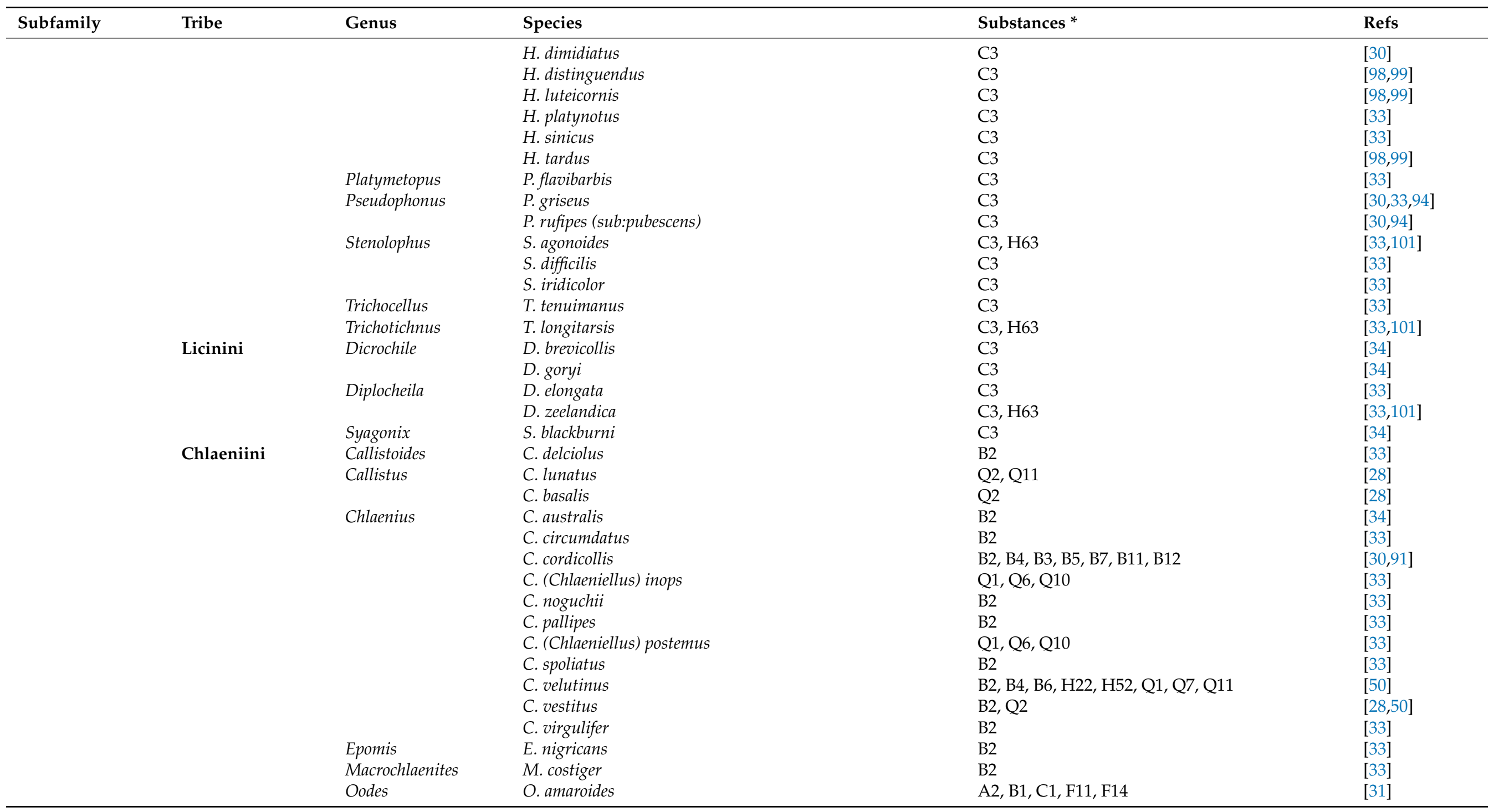


Table 2. Cont.

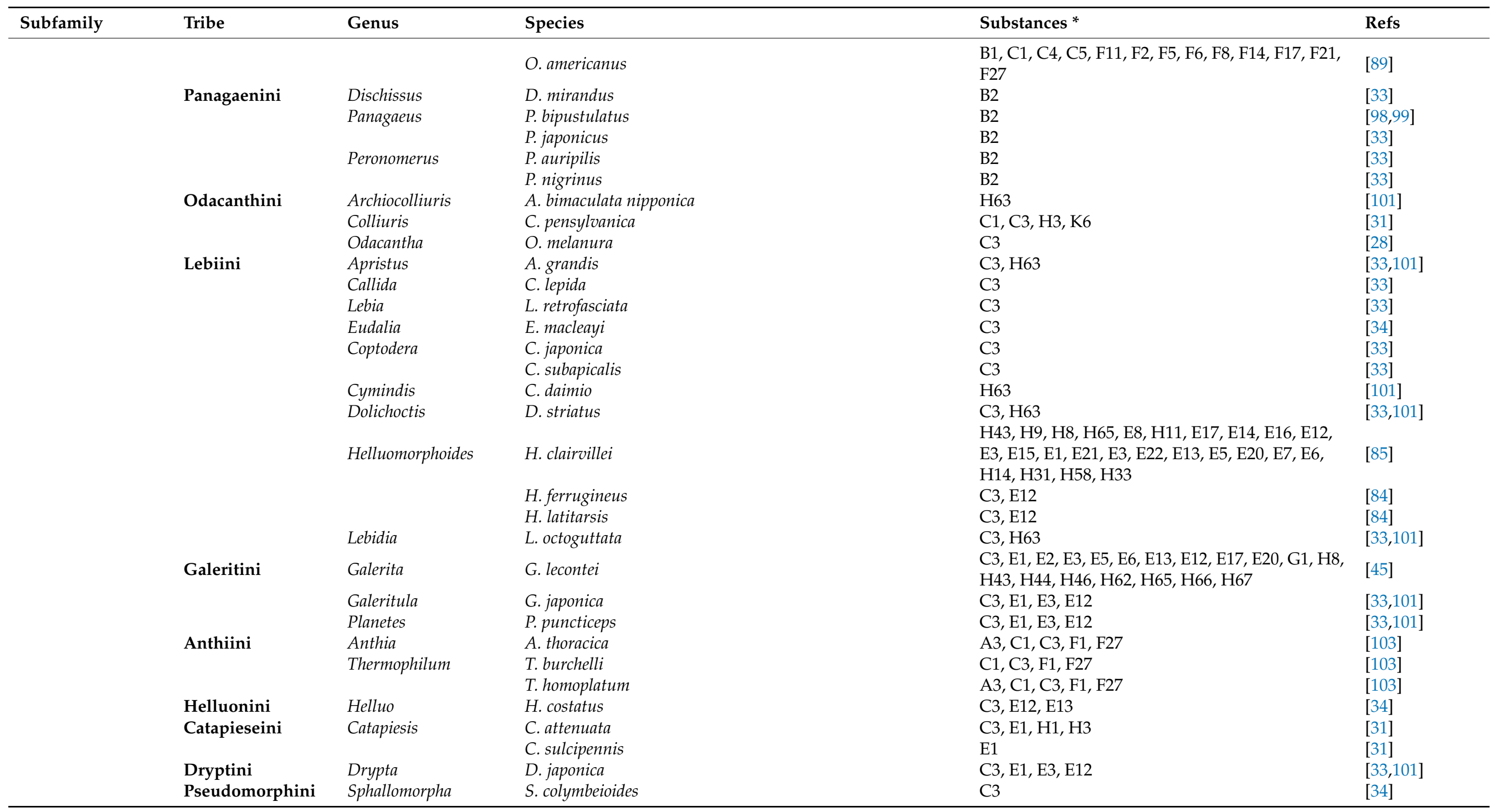


Table 2. Cont.

\begin{tabular}{|c|c|c|c|c|c|}
\hline Subfamily & Tribe & Genus & Species & Substances * & Refs \\
\hline \multirow[t]{11}{*}{ Brachininae } & Brachinini & Brachinus & B. chuji & Q1, Q9 & [33] \\
\hline & & & B. crepitans & $\mathrm{Q} 2, \mathrm{Q} 11$ & {$[28,30]$} \\
\hline & & & B. elongatus & H10, H14, H60, Q2, Q4, Q5, Q8, Q11, Q12 & {$[41,55,66]$} \\
\hline & & & B. explodens & Q2, Q11 & {$[28,30]$} \\
\hline & & & B. sclopeta & Q2, Q11 & {$[30,41]$} \\
\hline & & & B. scotomedes & Q1, Q9 & {$[33]$} \\
\hline & & & B. stenoderus & Q1, Q9 & {$[33]$} \\
\hline & & Pheropsophus & P. africanus & $\mathrm{N} 2, \mathrm{~N} 3$ & {$[30,41]$} \\
\hline & & & P. catoirei & Q2, Q11 & [104] \\
\hline & & & P. verticalis & Q1, Q11 & [34] \\
\hline & & & P. jessoensis & Q1, Q9 & {$[33]$} \\
\hline
\end{tabular}

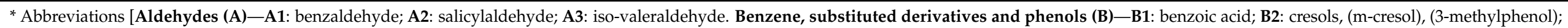

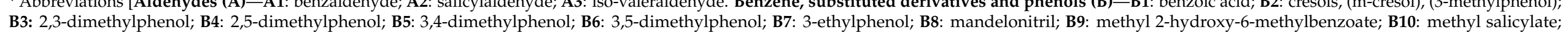

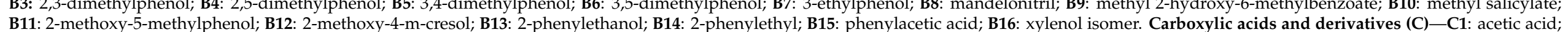

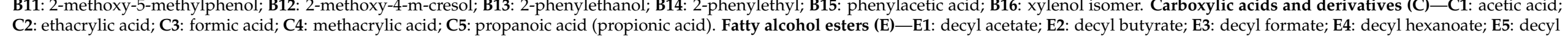

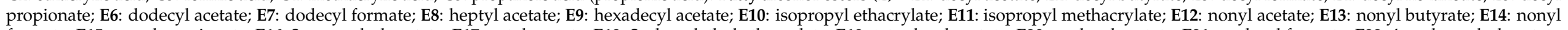

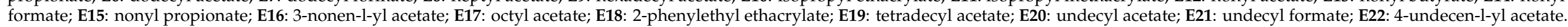

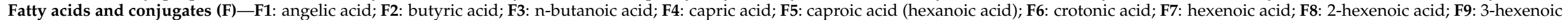

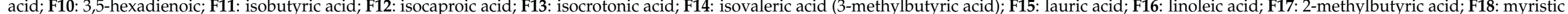

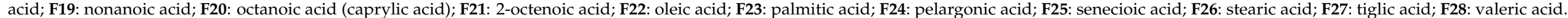

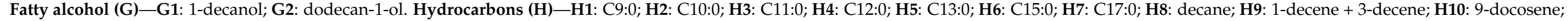

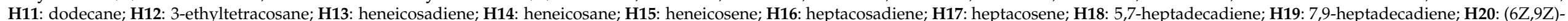

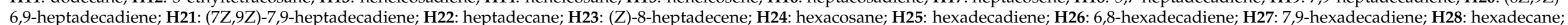

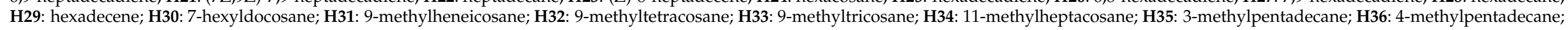

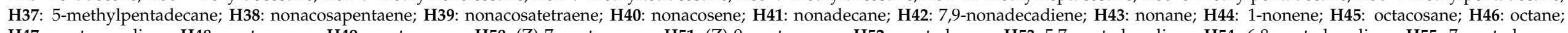

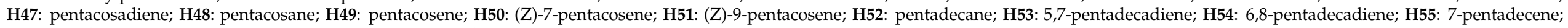

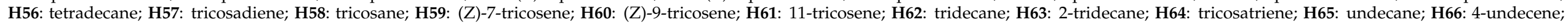

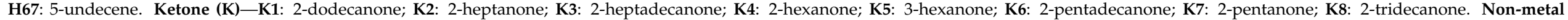

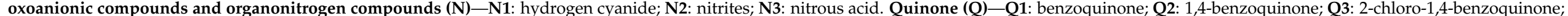

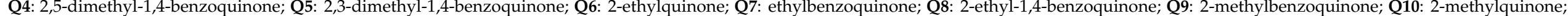

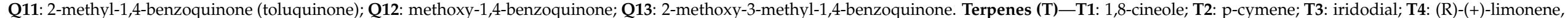
(S)-(-)-limonene; T5: sabinene; T6: $\beta$-phellandrene; T7: $\beta$-pinene. Thioethers (S)-S1: 3-methyl-1-(methylthio)-2-butene.]. 


\section{Concluding Remarks}

Pygidial glands are homologous structures in the Carabidae. They show a range of morphological variations in structural elements, i.e., number of acini, the morphology of ducts and reservoir chamber, and mode of secretion discharge, among carabid species, regardless of habitat and associated ecological differences. Chemical defences are an important part of antipredator strategies in ground beetles. Prey-predator coevolution likely influences glandular secretion composition, which is the result of a trade-off between the predator diversity and the fitness costs of defending against these enemies. A great deal of interspecific diversity in the distribution of substances has been found in subfamilies. Some chemicals are readily identifiable as specific to particular taxa, while others show great species-level diversity among genera or tribes. These results are broadly consistent with previous studies in which the taxonomic distribution of compound secretion was reviewed according to habitat diversification and by mapping chemical classes in a phylogenetic context $[31,33]$. However, some elements need to be considered in the future interpretation of the taxonomic distribution of chemicals. The findings pertain to only the $4 \%$ of carabid species so far described, and further studies are needed to clarify differences in chemical composition in additional taxa. A large number of studies reported only the most abundant chemicals, neglecting compounds that are present in smaller percentages and have additional biological functions in the mixture, e.g., surfactants, pheromones, and antiseptic agents. In addition, the differences found in some chemical profiles may be related to the number of samples analysed as single or mixed samples or to the accuracy of the gas chromatographic equipment used in early studies. Finally, we recommend that further research should address to elucidate: (1) the biogenesis of all chemicals described in the pygidial glands and their function in an ecological context; (2) clarify the phylogenetic distribution patterns of chemicals by studying as many species as possible using comparable protocols; (3) the sexual dimorphism of the secretion with regard to the different degree of resource allocation between the sexes under the pressure of environmental selection.

Author Contributions: Conceptualisation, A.G.; data curation, F.T. and M.L.V.; validation of taxonomy, P.B.; writing—original draft preparation, A.G.; writing—review and editing: A.G., M.L.V. and F.T. All authors have read and agreed to the published version of the manuscript.

Funding: This research received no external funding.

Institutional Review Board Statement: Not applicable.

Informed Consent Statement: Not applicable.

Data Availability Statement: No new data were created or analyzed in this study. Data sharing is not applicable to this article.

Conflicts of Interest: The authors declare no conflict of interest. The funders had no role in the design of the study; in the collection, analyses, or interpretation of data; in the writing of the manuscript, or in the decision to publish the results.

\section{References}

1. Holland, J.M. The Agroecology of Carabid Beetles; Intercept Limited: Andover, UK, 2002; Volume 62, ISBN 1898298769.

2. Lövei, G.L.; Sunderland, K.D. Ecology and behavior of ground beetles (Coleoptera: Carabidae). Annu. Rev. Entomol. 1996, 41, 231-256. [CrossRef] [PubMed]

3. Koivula, M.J. Useful model organisms, indicators, or both? Ground beetles (Coleoptera, Carabidae) reflecting environmental conditions. ZooKeys 2011, 287-317. [CrossRef] [PubMed]

4. Rainio, J.; Niemelä, J. Ground beetles (Coleoptera: Carabidae) as bioindicators. Biodivers. Conserv. 2003, 12, 487-506. [CrossRef]

5. Avgın, S.S.; Luff, M.L. Ground beetles (Coleoptera: Carabidae) as bioindicators of human impact. Munis Entomol. Zool. 2010, 5, 209-215.

6. Ghannem, S.; Touaylia, S.; Boumaiza, M. Beetles (Insecta: Coleoptera) as bioindicators of the assessment of environmental pollution. Hum. Ecol. Risk Assess. Int. J. 2018, 24, 456-464. [CrossRef]

7. Tooming, E.; Merivee, E.; Must, A.; Merivee, M.-I.; Sibul, I.; Nurme, K.; Williams, I.H. Behavioural effects of the neonicotinoid insecticide thiamethoxam on the predatory insect Platynus assimilis. Ecotoxicology 2017, 26, 902-913. [CrossRef] 
8. Giglio, A.; Cavaliere, F.; Giulianini, P.G.; Kurtz, J.; Vommaro, M.L.; Brandmayr, P. Continuous agrochemical treatments in agroecosystems can modify the effects of pendimethalin-based herbicide exposure on immunocompetence of a beneficial ground beetle. Diversity 2019, 11, 241. [CrossRef]

9. Butovsky, R.O. Heavy metals in carabids (Coleoptera, Carabidae). ZooKeys 2011, 100, 215-222. [CrossRef]

10. Talarico, F.; Brandmayr, P.; Giulianini, P.G.; Ietto, F.; Naccarato, A.; Perrotta, E.; Tagarelli, A.; Giglio, A. Effects of metal pollution on survival and physiological responses in Carabus (Chaetocarabus) lefebvrei (Coleoptera, Carabidae). Eur. J. Soil Biol. 2014, 61, 80-89. [CrossRef]

11. Tőzsér, D.; Magura, T.; Simon, E.; Mizser, S.; Papp, D.; Tóthmérész, B. Pollution intensity-dependent metal accumulation in ground beetles: A meta-analysis. Environ. Sci. Pollut. Res. 2019, 26, 32092-32102. [CrossRef]

12. Naccarato, A.; Tassone, A.; Cavaliere, F.; Elliani, R.; Pirrone, N.; Sprovieri, F.; Tagarelli, A.; Giglio, A. Agrochemical treatments as a source of heavy metals and rare earth elements in agricultural soils and bioaccumulation in ground beetles. Sci. Total Environ. 2020, 749, 141438. [CrossRef]

13. Giglio, A.; Brandmayr, P. Structural and functional alterations in Malpighian tubules as biomarkers of environmental pollution: Synopsis and prospective. J. Appl. Toxicol. 2017, 37, 889-894. [CrossRef] [PubMed]

14. De Heij, S.E.; Willenborg, C.J. Connected carabids: Network interactions and their impact on biocontrol by carabid beetles. BioScience 2020, 70, 490-500. [CrossRef] [PubMed]

15. Kulkarni, S.S.; Dosdall, L.M.; Willenborg, C.J. The role of ground beetles (Coleoptera: Carabidae) in weed seed consumption: A review. Weed Sci. 2015, 63, 355-376. [CrossRef]

16. Fukuda, S.; Konuma, J. Using three-dimensional printed models to test for aposematism in a carabid beetle. Biol. J. Linn. Soc. 2019, 128, 735-741. [CrossRef]

17. Schultz, T.D. Tiger beetle defenses revisited: Alternative defense strategies and colorations of two neotropical tiger beetles, Odontocheila nicaraguensis Bates and Pseudoxycheila tarsalis Bates (Carabidae: Cicindelinae). Coleopt. Bull. 2001, 153-163. [CrossRef]

18. Hasegawa, M.; Taniguchi, Y. Visual avoidance of a conspicuously colored carabid beetle Dischissus mirandus by the lizard Eumeces okadae. J. Ethol. 1994, 12, 9-14. [CrossRef]

19. Brandmayr, P.; Bonacci, T.; Giglio, A.; Talarico, F.F.; Brandmayr, T.Z. The evolution of defence mechanisms in carabid beetles: A review. In Life and Time: The Evolution of Life and its History; Cleup: Padova, Italy, 2009; pp. 25-43. ISBN 9788861294110.

20. Talarico, F.; Brandmayr, P.; Giglio, A.; Massolo, A.; Brandmayr, T.Z. Morphometry of eyes, antennae and wings in three species of Siagona (Coleoptera, Carabidae). ZooKeys 2011, 100, 203-214. [CrossRef]

21. Whitman, D.W.; Blum, M.S.; Alsop, D.W. Allomones: Chemicals for defense. Insect Def. Adapt. Mech. Strateg. Prey Predat. 1990, $289,289-351$.

22. Dettner, K. Chemosystematics and evolution of beetle chemical defenses. Annu. Rev. Entomol. 1987, 32, 17-48. [CrossRef]

23. Giglio, A.; Brandmayr, P.; Talarico, F.; Brandmayr, T.Z. Current knowledge on exocrine glands in carabid beetles: Structure, function and chemical compounds. ZooKeys 2011, 100, 193-201. [CrossRef]

24. Evans, D.L.; Schmidt, J.O. Insect Defenses: Adaptive Mechanisms and Strategies of Prey and Predators; SUNY Press: Albany, NY, USA, 1990; ISBN 1438402201.

25. Blum, M.S. Semiochemical parsimony in the Arthropoda. Annu. Rev. Entomol. 1996, 41, 353-374. [CrossRef]

26. Lečić, S.; Ćurčić, S.; Vujisić, L.; Ćurčić, B.; Ćurčić, N.; Nikolić, Z.; Anelković, B.; Milosavljević, S.; Tešević, V.; Makarov, S. Defensive secretions in three ground-beetle species (Insecta: Coleoptera: Carabidae). Proc. Ann. Zool. Fenn. 2014, 51, 285-300. [CrossRef]

27. Rork, A.M.; Renner, T. Carabidae semiochemistry: Current and future directions. J. Chem. Ecol. 2018, 44, 1069-1083. [CrossRef] [PubMed]

28. Blum, M. Chemical defenses of Arthropods. In Chemical Defenses of Arthropods; Blum, M.S., Ed.; Academic Press: New York, NY, USA, 1981; p. 561. ISBN 978-0-12-108380-9.

29. Erwin, T.L.; Ball, G.E.; Whitehead, D.R.; Halpern, A.L. Carabid Beetles: Their Evolution, Natural History, and Classification; Springer Science \& Business Media: Dordrecht, The Netherlands, 2012; ISBN 9400996284.

30. Dazzini-Valcurone, M.; Pavan, M. Glandole pigidiali e secrezioni difensive dei Carabidae (Insecta Coleoptera). Publicazioni Dell'istituto Di Entomol. Dell'universita Di Pavia 1980, 12, 1-36.

31. Will, K.W.; Attygalle, A.B.; Herath, K. New defensive chemical data for ground beetles (Coleoptera: Carabidae): Interpretations in a phylogenetic framework. Biol. J. Linn. Soc. 2000, 71, 459-481. [CrossRef]

32. Moore, B.P. Chemical defense in carabids and its bearing on phylogeny. In Carabid Beetles; Springer: Dordrecht, The Netherlands, 1979; pp. 193-203.

33. Kanehisa, K.; Murase, M. Comparative study of the pygidial defensive systems of carabid beetles. Appl. Entomol. Zool. 1977, 12, 225-235. [CrossRef]

34. Moore, B.P.; Wallbank, B.E. Chemical composition of the defensive secretion in carabid beetles and its importance as a taxonomic character. In Proceedings of the Royal Entomological Society of London. Series B, Taxonomy; Wiley Online Library: Oxford, UK, 1968; Volume 37, pp. 62-72.

35. Forsyth, D.J. The structure of the pygidial defence glands of Carabidae (Coleoptera). Trans. Zool. Soc. Lond. 1972, 32, 249-309. [CrossRef]

36. Noirot, C.; Quennedey, A. Fine Structure of Insect Epidermal Glands. Annu. Rev. Entomol. 1974, 19, 61-80. [CrossRef] 
37. Noirot, C.; Quennedey, A. Glands, gland cells, glandular units: Some comments on terminology and classification. In Annales De La Societe Entomologique De France; Société entomologique de France: Paris, France, 1991; Volume 27, pp. 123-128.

38. Forsyth, D.J. The ultrastructure of the pygidial defence glands of the carabid Pterostichus madidus F. J. Morphol. 1970, 131, 397-415. [CrossRef]

39. Muzzi, M.; Moore, W.; Di Giulio, A. Morpho-functional analysis of the explosive defensive system of basal bombardier beetles (Carabidae: Paussinae: Metriini). Micron 2019, 119, 24-38. [CrossRef] [PubMed]

40. Muzzi, M.; Di Giulio, A. The ant nest "bomber": Explosive defensive system of the flanged bombardier beetle Paussus favieri (Coleoptera, Carabidae). Arthropod Struct. Dev. 2019, 50, 24-42. [CrossRef]

41. Di Giulio, A.; Muzzi, M.; Romani, R. Functional anatomy of the explosive defensive system of bombardier beetles (Coleoptera, Carabidae, Brachininae). Arthropod Struct. Dev. 2015, 44, 468-490. [CrossRef] [PubMed]

42. Vesović, N.; Vujisić, L.; Perić-Mataruga, V.; Krstić, G.; Nenadić, M.; Cvetković, M.; Ilijin, L.; Stanković, J.; Ćurčić, S. Chemical secretion and morpho-histology of the pygidial glands in two Palaearctic predatory ground beetle species: Carabus (Tomocarabus) convexus and C. (Procrustes) coriaceus (Coleoptera: Carabidae). J. Nat. Hist. 2017, 51, 545-560. [CrossRef]

43. Vesović, N.; Ćurčić, S.; Todosijević, M.; Nenadić, M.; Zhang, W.; Vujisić, L. Pygidial gland secretions of Carabus Linnaeus, 1758 (Coleoptera: Carabidae): Chemicals released by three species. Chemoecology 2020, 30, 59-68. [CrossRef]

44. Vranić, S.; Ćurčić, S.; Vesović, N.; Mandić, B.; Pantelić, D.; Vasović, M.; Lazović, V.; Zhang, W.; Vujisić, L. Chemistry and morphology of the pygidial glands in four Pterostichini ground beetle taxa (Coleoptera: Carabidae: Pterostichinae). Zoology 2020, 142, 125772. [CrossRef]

45. Rossini, C.; Attygalle, A.B.; González, A.; Smedley, S.R.; Eisner, M.; Meinwald, J.; Eisner, T. Defensive production of formic acid (80\%) by a carabid beetle (Galerita lecontei). Proc. Natl. Acad. Sci. USA 1997, 94, 6792-6797. [CrossRef]

46. Deuve, T. L'abdomen et les genitalia des femelles de Coleopteres Adephaga. Mem. Du Mus. Natl. D’histoire Nat. Paris 1993, $155,1-184$

47. Forsyth, D.J. The structure of the defence glands of the Cicindelidae, Amphizoidae, and Hygrobiidae (Insecta: Coleoptera). J. Zool. 1970, 160, 51-69. [CrossRef]

48. Nenadić, M.; Soković, M.; Glamočlija, J.; Ćirić, A.; Perić-Mataruga, V.; Ilijin, L.; Tešević, V.; Todosijević, M.; Vujisić, L.; Vesović, N.; et al. The pygidial gland secretion of the forest caterpillar hunter, Calosoma (Calosoma) sycophanta: The antimicrobial properties against human pathogens. Appl. Microbiol. Biotechnol. 2017, 101, 977-985. [CrossRef]

49. Nenadić, M.; Soković, M.; Glamočlija, J.; Ćirić, A.; Perić-Mataruga, V.; Ilijin, L.; Tešević, V.; Vujisić, L.; Todosijević, M.; Vesović, N. Antimicrobial activity of the pygidial gland secretion of three ground beetle species (Insecta: Coleoptera: Carabidae). Sci. Nat. 2016, 103, 34. [CrossRef]

50. Balestrazzi, E.; Valcurone Dazzini, M.L.; De Bernardi, M.; Vidari, G.; Vita-Finzi, P.; Mellerio, G. Morphological and chemical studies on the pygidial defence glands of some Carabidae (Coleoptera). Naturwissenschaften 1985, 72, 482-484. [CrossRef]

51. Davidson, B.S.; Eisner, T.; Witz, B.; Meinwald, J. Defensive secretion of the carabid beetle Pasimachus subsulcatus. J. Chem. Ecol. 1989, 15, 1689-1697. [CrossRef]

52. Witz, B.W.; Mushinsky, H.R. Pygidial secretions of Pasimachus subsulcatus (Coleoptera: Carabidae) deter predation by Eumeces inexpectatus (Squamata: Scincidae). J. Chem. Ecol. 1989, 15, 1033-1044. [CrossRef] [PubMed]

53. Donato, S.; Vommaro, M.L.; Tromba, G.; Giglio, A. Synchrotron X-ray phase contrast micro tomography to explore the morphology of abdominal organs in Pterostichus melas italicus Dejean, 1828 (Coleoptera, Carabidae). Arthropod Struct. Dev. 2021, 62, 101044. [CrossRef]

54. Rork, A.M.; Mikó, I.; Renner, T. Pygidial glands of Harpalus pensylvanicus (Coleoptera: Carabidae) contain resilin-rich structures. Arthropod Struct. Dev. 2019, 49, 19-25. [CrossRef]

55. Arndt, E.M.; Moore, W.; Lee, W.K.; Ortiz, C. Mechanistic origins of Bombardier beetle (Brachinini) explosion-induced defensive spray pulsation. Science 2015, 348, 563-567. [CrossRef]

56. Bousquet, Y. Catalogue of Geadephaga (Coleoptera, Adephaga) of America, north of Mexico. ZooKeys 2012, 1-1630. [CrossRef] [PubMed]

57. Beutel, R.G.; Ribera, I.; Fikáček, M.; Vasilikopoulos, A.; Misof, B.; Balke, M. The morphological evolution of the Adephaga (Coleoptera). Syst. Entomol. 2020, 45, 378-395. [CrossRef]

58. Thiele, H.-U. Carabid Beetles in Their Environments: A Study on Habitat Selection by Adaptations in Physiology and Behaviour; Springer Science \& Business Media: Dordrecht, The Netherland, 1977; Volume 10, ISBN 364281154X.

59. Roach, B.; Dodge, K.R.; Aneshansley, D.J.; Wiemer, D.; Meinwald, J.; Eisner, T. Chemistry of defensive secretions of Ozaenine and Paussine bombardier beetles (Coleoptera: Carabidae). Coleopt. Bull. 1979, 33, 17-20.

60. Aneshansley, D.J.; Eisner, T.; Widom, J.M.; Widom, B. Biochemistry at $100{ }^{\circ} \mathrm{C}$ : Explosive secretory discharge of bombardier beetles (Brachinus). Science 1969, 165, 61-63. [CrossRef]

61. Eisner, T.; Aneshansley, D.J. Spray aiming in the bombardier beetle: Photographic evidence. Proc. Natl. Acad. Sci. USA 1999, 96, 9705-9709. [CrossRef]

62. Eisner, T.; Aneshansley, D.J.; Eisner, M.; Attygalle, A.B.; Alsop, D.W.; Meinwald, J. Spray mechanism of the most primitive bombardier beetle (Metrius contractus). J. Exp. Biol. 2000, 203, 1265-1275. [CrossRef]

63. Eisner, T.; Aneshansley, D.J. Spray aiming in bombardier beetles: Jet deflection by the coanda effect. Science 1982, $215,83-85$. [CrossRef] 
64. Eisner, T.; Swithenbank, C.; Meinwald, J. Defense Mechanisms of Arthropods. VIII. Secretion of salicylaldehyde by a carabid beetle. Ann. Entomol. Soc. Am. 1963, 56, 37-41. [CrossRef]

65. Blum, M.S. Biosynthesis of arthropod exocrine compounds. Annu. Rev. Entomol. 1987, 32, 381-413. [CrossRef]

66. Attygalle, A.B.; Xu, S.; Moore, W.; McManus, R.; Gill, A.; Will, K. Biosynthetic origin of benzoquinones in the explosive discharge of the bombardier beetle Brachinus elongatulus. Sci. Nat. 2020, 107, 1-11. [CrossRef] [PubMed]

67. Benn, M.H.; Lencucha, A.; Maxie, S.; Telang, S.A. The pygidial defensive secretion of Carabus taedatus. J. Insect Physiol. 1973, 19, 2173-2176. [CrossRef]

68. Attygalle, A.B.; Meinwald, J.; Eisner, T. Biosynthesis of methacrylic acid and isobutyric acids in a carabid beetle, Scarites subterraneus. Tetrahedron Lett. 1991, 32, 4849-4852. [CrossRef]

69. Attygalle, A.B.; Wu, X.; Will, K.W. Biosynthesis of tiglic, ethacrylic, and 2-methylbutyric acids in a carabid beetle, Pterostichus (Hypherpes) Californicus. J. Chem. Ecol. 2007, 33, 963-970. [CrossRef] [PubMed]

70. Chapman, R.F. The Insects: Structure and Function; Cambridge University Press: Cambridge, UK, 2012 ; ISBN 1107310458.

71. Pasteels, J.M.; Gregoire, J.C.; Rowell-Rahier, M. The chemical ecology of defense in arthropods. Annu. Rev. Entomol. 1983, 28, 263-289. [CrossRef]

72. Kojima, W.; Yamamoto, R. Defense of bombardier beetles against avian predators. Sci. Nat. 2020, 107, 1-5. [CrossRef]

73. Sugiura, S. Anti-predator defences of a bombardier beetle: Is bombing essential for successful escape from frogs? PeerJ 2018, 2018, e5942. [CrossRef] [PubMed]

74. Geiselhardt, S.F.; Peschke, K.; Nagel, P. A review of myrmecophily in ant nest beetles (Coleoptera: Carabidae: Paussinae): Linking early observations with recent findings. Naturwissenschaften 2007, 94, 871-894. [CrossRef]

75. Attygalle, A.B.; Wu, X.; Maddison, D.R.; Will, K.W. Orange/lemon-scented beetles: Opposite enantiomers of limonene as major constituents in the defensive secretion of related carabids. Naturwissenschaften 2009, 96, 1443-1449. [CrossRef] [PubMed]

76. Claridge, M.F. Stridulation and defensive behaviour in the ground beetle, Cychrus caraboides (L.). J. Entomol. Ser. A Gen. Entomol. 1974, 49, 7-15. [CrossRef]

77. Wheeler, J.W.; Chung, R.H.; Oh, S.K.; Benfield, E.F.; Neff, S.E. Defensive Secretions of Cychrine Beetles (Coleoptera: Carabidae). Ann. Entomol. Soc. Am. 1970, 63, 469-471. [CrossRef]

78. Schildknecht, H. Die Wehrchemie von Land- und Wasserkäfern. Angew. Chem. 1970, 82, 17-25. [CrossRef]

79. Pearson, D.L.; Blum, M.S.; Jones, T.H.; Fales, H.M.; Gonda, E.; Witte, B.R. Historical perspective and the interpretation of ecological patterns: Defensive compounds of tiger beetles (Coleoptera: Cicindelidae). Am. Nat. 1988, 132, 404-416. [CrossRef]

80. Kelley, K.C.; Schilling, A.B. Quantitative Variation in chemical defense within and among subgenera of Cicindela. J. Chem. Ecol. 1998, 24, 451-472. [CrossRef]

81. Blum, M.S.; Jones, T.H.; House, G.J.; Tschinkel, W.R. Defensive secretions of tiger beetles: Cyanogenetic basis. Comp. Biochem. Physiol. Part B Comp. Biochem. 1981, 69, 903-904. [CrossRef]

82. Pearson, D.L. The function of multiple anti-predator mechanisms in adult tiger beetles (Coleoptera: Cicindelidae). Ecol. Entomol. 1985, 10, 65-72. [CrossRef]

83. Pearson, D.L. The Evolution of multi anti-predator characteristics as illustrated by tiger beetles (Coleoptera: Cicindelidae). Fla. Entomol. 1990, 73, 67-70. [CrossRef]

84. Eisner, T.; Meinwald, Y.C.; Alsop, D.W.; Carrel, J.E. Defense Mechanisms of Arthropods. XXI. Formic Acid and n-Nonyl Acetate in the Defensive Spray of Two Species of Helluomorphoides. Ann. Entomol. Soc. Am. 1968, 61, 610-613. [CrossRef]

85. Attygalle, A.B.; Meinwald, J.; Eisner, T. Defensive secretion of a carabid beetle, Helluomorphoides clairvillei. J. Chem. Ecol. 1992, 18, 489-498. [CrossRef]

86. Nenadić, M.; Soković, M.; Calhelha, R.C.; Ferreira, I.C.F.R.; Ćirić, A.; Vesović, N.; Ćurčić, S. Inhibition of tumour and non-tumour cell proliferation by pygidial gland secretions of four ground beetle species (Coleoptera: Carabidae). Biologia 2018, 73, 787-792. [CrossRef]

87. Dimkić, I.; Stanković, S.; Kabić, J.; Stupar, M.; Nenadić, M.; Ljaljević-Grbić, M.; Žikić, V.; Vujisić, L.; Tešević, V.; Vesović, N.; et al. Bat guano-dwelling microbes and antimicrobial properties of the pygidial gland secretion of a troglophilic ground beetle against them. Appl. Microbiol. Biotechnol. 2020, 104, 4109-4126. [CrossRef] [PubMed]

88. Giglio, A.; Brandmayr, P.; Dalpozzo, R.; Sindona, G.; Tagarelli, A.; Talarico, F.; Brandmayr, T.Z.; Ferrero, E.A. The Defensive Secretion of Carabus lefebvrei Dejean 1826 Pupa (Coleoptera, Carabidae): Gland ultrastructure and chemical identification. Microsc. Res. Tech. 2009, 72, 351-361. [CrossRef] [PubMed]

89. Attygalle, A.B.; Meinwald, J.; Liebherr, J.K.; Eisner, T. Sexual dimorphism in the defensive secretion of a carabid beetle. Experientia 1991, 47, 296-299. [CrossRef]

90. Holliday, A.E.; Mattingly, T.M.; Toro, A.A.; Donald, L.J.; Holliday, N.J. Age- and sex-related variation in defensive secretions of adult Chlaenius cordicollis and evidence for their role in sexual communication. Chemoecology 2016, 26, 107-119. [CrossRef]

91. Holliday, A.E.; Holliday, N.J.; Mattingly, T.M.; Naccarato, K.M. Defensive Secretions of the carabid beetle Chlaenius cordicollis: Chemical components and their geographic patterns of variation. J. Chem. Ecol. 2012, 38, 278-286. [CrossRef] [PubMed]

92. Schildknecht, H.; Koob, K. Zur explosionschemie der Bombardierkäfer. Naturwissenschaften 1969, 56, 328. [CrossRef]

93. Hefetz, A.; Lloyd, H.A.; Valdenberg, A. The defensive secretion of the tiger beetle Cicindela flexuosa (F.)(Cicindelinae; Carabidae). Experientia 1984, 40, 539-540. [CrossRef]

94. Jacobson, M. Chemical insect attractants and repellents. Annu. Rev. Entomol. 1966, 11, 403-422. [CrossRef] 
95. Schildknecht, H.; Holoubek, K.; Weis, K.H.; Krämer, H. Defensive substances of the arthropods, their isolation and identification. Angew. Chem. Int. Ed. Engl. 1964, 3, 73-82. [CrossRef]

96. Xu, S.; Errabeli, R.; Will, K.; Arias, E.; Attygalle, A.B. 3-Methyl-1-(methylthio)-2-butene: A component in the foul-smelling defensive secretion of two Ceroglossus species (Coleoptera: Carabidae). Chemoecology 2019, 29, 171-178. [CrossRef]

97. Moore, B.P.; Brown, W. V Chemical composition of the defensive secretion in Dyschirius bonelli (Coleoptera: Carabidae: Scarittnae) and its taxonomic significance. Aust. J. Entomol. 1979, 18, 123-125. [CrossRef]

98. Schildknecht, H.; Winkler, H.; Maschwitz, U. Vergleichend chemische Untersuchungen der Inhaltsstoffe der Pygidialwehrblasen von Carabiden. Z. Für Nat. B 1968, 23, 637-644. [CrossRef]

99. Schildknecht, H.; Maschwitz, U.; Winkler, H. Zur Evolution der Carabiden-Wehrdrüsensekrete. Naturwissenschaften 1968, 55, 112-117. [CrossRef]

100. Vesović, N.; Ćurčić, S.; Vujisić, L.; Nenadić, M.; Krstić, G.; Perić-Mataruga, V.; Milosavljević, S.; Antić, D.; Mandić, B.; Petković, M. Molecular diversity of compounds from pygidial gland secretions of cave-dwelling ground beetles: The first evidence. J. Chem. Ecol. 2015, 41, 533-539. [CrossRef] [PubMed]

101. Kanehisa, K.; Kawazu, K. Differences in neutral components of the defensive secretion in formic acid-secreting carabid beetles. Appl. Entomol. Zool. 1985, 20, 299-304. [CrossRef]

102. Will, K.W.; Gill, A.S.; Lee, H.; Attygalle, A.B. Quantification and evidence for mechanically metered release of pygidial secretions in formic acid-producing carabid beetles. J. Insect Sci. 2010, 10, 12. [CrossRef] [PubMed]

103. Scott, P.D.; Hepburn, H.R.; Crewe, R.M. Pygidial defensive secretions of some carabid beetles. Insect Biochem. 1975, 5, 805-811. [CrossRef]

104. Schildknecht, H.; Holoubek, K. Die Bombardierkäfer und ihre Explosionschemie V. Mitteilung über Insekten-Abwehrstoffe. Angew. Chem. 1961, 73, 1-7. [CrossRef] 